\title{
Cytotoxicity and radiosensitization effect of TRA-8 on radioresistant human larynx squamous carcinoma cells
}

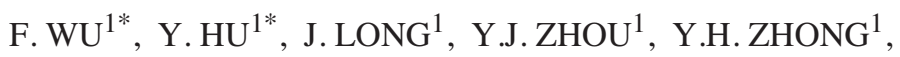

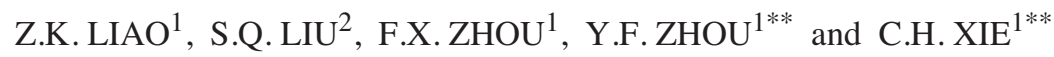 \\ ${ }^{1}$ Department of Radiation and Medical Oncology, Zhongnan Hospital, Wuhan University, \\ ${ }^{2}$ Hubei Key Laboratory of Tumor Biological Behaviors, Wuhan 430071, P.R. China
}

Received September 10, 2008; Accepted October 20, 2008

DOI: $10.3892 /$ or_00000245

\begin{abstract}
TRAIL induces apoptosis in a variety of tumorigenic and transformed cell lines, but not in many normal cells. Recent studies have demonstrated that death receptor 5 (DR5), one of the two death receptors bound by TRAIL, showed expression in most malignantly transformed cells. This study evaluated effects of a monoclonal antibody (TRA-8) to human death receptor 5, combined with ionizing radiation, on radioresistant human larynx squamous carcinoma cell line (Hep-2R). Cells were treated with TRA- 8 alone or in combination with radiation, cell viability inhibition was measured by MTT assay, and the induction of apoptosis was determined by Annexin V staining. Radionsensitivity of Hep-2R cells treated with TRA-8 were investigated with long-term clonogenic assays. Regulation of DR5 expression in cells after radiation was analyzed by indirect immunofluorescence using murine TRA-8 in combination with flow cytometry. The results suggested that TRA-8 enhanced radionsensitivity of Hep-2R cells, and that TRA- 8 regulated Hep-2R cell cycle arrest at G2/M phase. Irradiation up-regulated the expression of DR5, and when combined with TRA- 8 yielded optimal survival benefit. Therefore, TRA- 8 can be used in combination with irradiation in radioresistant human larynx squamous carcinoma cells. Monoclonal antibodies such as TRA-8 may play an important role in the
\end{abstract}

Correspondence to: Dr Conghua Xie, Department of Radiation and Medical Oncology, Zhongnan Hospital, Wuhan University, Wuhan 430071, P.R. China

E-mail: chxie_65@hotmail.com

*Contributed equally; ${ }^{* *}$ Shared senior authorship

Abbreviations: TRAIL, tumor necrosis factor related apoptosisinducing ligand; DR, death receptor; DcR, decoy receptor; PI, propidium iodide; FITC, fluorescein isothiocyanate; DMSO, dimethyl sulphoxide; MTT, 3-(4, 5-dimethylthiazol-2-yl)-2,5diphenyl tetrazolium bromide

Key words: TRAIL, TRA-8, radiosensitivity, radioresistant, larynx carcinoma development of an effective treatment strategy for patients with radioresistant cancers.

\section{Introduction}

Radiotherapy plays an important role in the treatment for cancers. Nevertheless, some radioresistant cancer cell lines have recently been discovered. Treatment for radioresistant cancers has long been a clinical challenge. There are two hypotheses explaining the phenotypic heterogeneity of tumor cells in proliferation capability and radiosensitivity. One is 'radiation sieved in subgroup cells' (1), and the other is 'cell mutagenesis by irradiation' (2). In our previous study, we established a radioresistant tumor cell line (Hep-2R) and a radiosensitivity comparison model, with results supporting the first hypothesis (3). Research on the radioresistant cell model induced by repeated ionizing radiation suggests an effective treatment strategy for patients with cancers that are resistant to radiotherapy, including recurrent tumors in a short period after radiotherapy.

Tumor necrosis factor-related apoptosis-inducing ligand (TRAIL/Apo2L) is a promising anticancer agent due to its ability to induce apoptosis in many cancer cell lines, with minimal adverse effects on most normal cells (4). TRAIL is expressed constitutively in many normal tissues and is a type 2 transmembrane protein that can be cleaved by specific proteases to release its soluble form. At least five membrane receptors for TRAIL have been identified, and two of them (DR4 and DR5) are death receptor (5-8); the remaining three receptors are decoy receptors that are capable of blocking TRAIL-mediated apoptosis (9-11). The initial optimism for TRAIL was tempered somehow because studies with early recombinant forms of TRAIL also induced apoptosis in normal human hepatocytes (12). Although newer zinc-optimized recombinant forms of TRAIL have avoided such hepatotoxicity $(13,14)$, agonistic monoclonal antibodies to specific death receptors were developed in an effort to circumvent this observed toxicity $(15,16)$. Ichikawa developed TRA- 8 , a mouse monoclonal antibody that specifically binds to human DR5, without binding to DR4 or decoy receptors, which induced apoptosis of tumor cell lines in vitro, with tumoricidal effects in vivo (15).

Various tumor cells have been noted to have increased levels of cell-surface expression of DR5, thereby making these 
cells susceptible to DR5-mediated apoptosis (17-19). We hypothesize that DR5 on Hep-2R cells can be selectively targeted with TRA-8 to enhance the anti-tumor effects of ionizing radiation. The objective of this study was to determine the therapeutic potential of TRA-8 in combination with radiation therapy in Hep- $2 \mathrm{R}$ cells.

\section{Materials and methods}

Reagents. Antibody against DR5 was purchased from Jingmei Biotech Co., Ltd. (R\&D Systems, Inc.). LHK601-100/ Annexin V FITC kit was purchased from Jingmei Biotech Co., Ltd. (Bender Medsystems). FITC-conjugated goat antimouse IgG1 was purchased from Wuhan Boster Biological Technology, Ltd.

Cells and culture conditions. Hep-2R cells were established in our previous work (3). All media were supplemented with $2 \mathrm{mM}$ L-glutamine, $10 \%$ fetal calf serum and $1 \%$ penicillinstreptomycin and cells were cultured at $37^{\circ} \mathrm{C}$ with $5 \% \mathrm{CO}_{2}$.

Basal expression of DR5 in Hep-2R cells. Cells were grown in complete medium supplemented with $10 \%$ FBS. Cells in exponential growth phase were harvested, and were collected by centrifugation at $4^{\circ} \mathrm{C}$ for $5 \mathrm{~min}$ at $1,000 \mathrm{rpm}$, followed by resuspension in PBS at $4^{\circ} \mathrm{C}$. Cells were counted and aliquots of $5 \times 10^{5}$ cells were added to FACS tubes. Cells were recentrifuged and the pellet was resuspended in PBS. Cells were incubated with TRA-8 $(2 \mu \mathrm{g} / \mathrm{ml})$ for $40 \mathrm{~min}$ on ice followed by FITC-conjugated goat anti-mouse IgG antibody (Wuhan Boster Biological Technology, Ltd.). Cells were washed again with FACS buffer and were examined using flow cytometry (FACScan, Beckman Coulter). Data were analyzed using CellQuest software.

Assessment of apoptosis by Annexin-V staining. Hep-2R cells were plated in 6 -well culture plates at $3 \times 10^{5}$ cells/well and cultured overnight. Cells were treated with TRA-8 in different concentration, or an equal volume of media alone to serve as a negative control, incubated overnight at $37^{\circ} \mathrm{C}$. Then TRA- 8 was added, after $24 \mathrm{~h}$ cells were stained with annexin V and propidium iodide (PI) using an Annexin V-FITC apoptosis detection kit, according to the manufacturer's protocol. Cells were then analyzed using flow cytometry (FACScan Beckman Coulter). Data were analyzed with CellQuest software.

Synergistic cytotoxicity of TRA-8 in combination with ionizing radiation detected by MTT assay. Cells were seeded in 24-well plates at a concentration of $5 \times 10^{4}$ cells/well overnight and irradiated in different doses with ${ }^{60} \mathrm{Co} \gamma$-ray. After $24 \mathrm{~h}$, TRA-8 was added, and another $24 \mathrm{~h}$ later, $50 \mu \mathrm{l} /$ well of $5 \mathrm{mg} / \mathrm{ml}$ MTT solution (Amresco, USA) was added respectively. The medium was removed by centrifugation after $4 \mathrm{~h}$ of incubation at $37^{\circ} \mathrm{C}$ with $5 \% \mathrm{CO}_{2}$. The blue formazan product converted from MTT was dissolved by the addition of $150 \mu \mathrm{l} /$ well DMSO and OD readings were obtained using a microplate reader (Tecan, Austria) at $570 \mathrm{~nm}$. Cell viability was represented as a percentage of control cells [percent cell viability $=($ treated $/$ control) $\mathrm{x} 100]$.

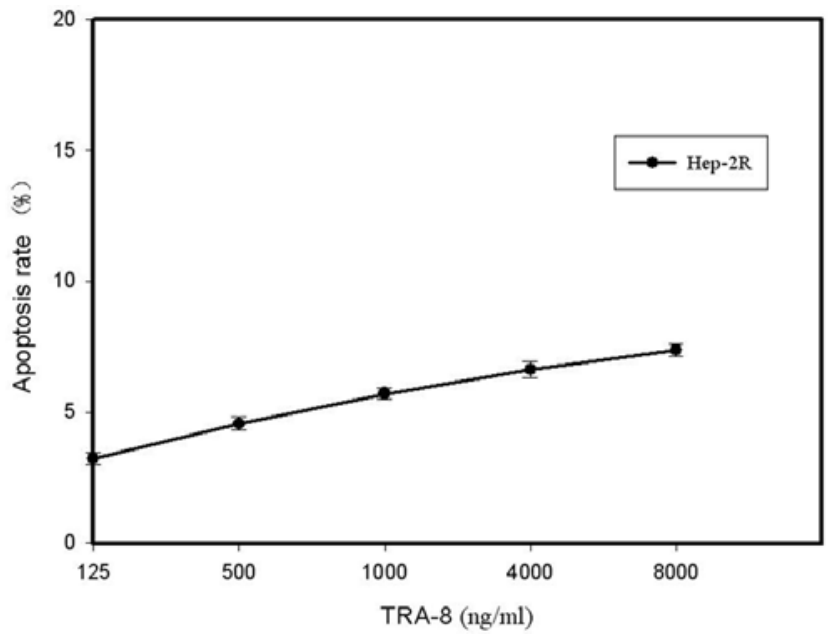

Figure 1. Cytotoxicity of TRA-8 against Hep-2R cells. Hep-2R Cells were plated in 6-well plates overnight, and were treated with TRA- 8 in different concentrations. Cells were harvested $24 \mathrm{~h}$ after TRA- 8 was added, and apoptosis was analyzed by Annexin-V-FITC staining. The mean in three independent experiments are shown.

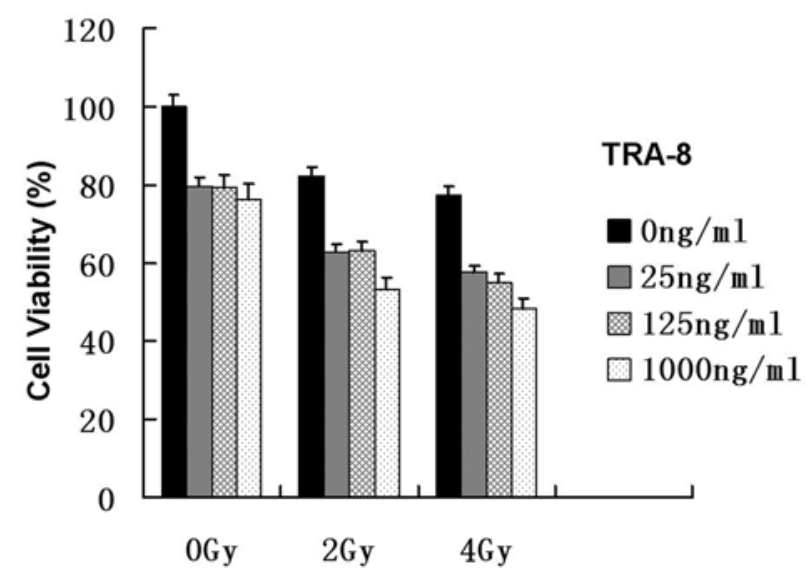

Figure 2. Cytotoxicity of TRA-8 in combination with radiation against Hep-2R cells. Cells were plated in 24-well plates and incubated overnight. Then cells were exposed to ${ }^{60} \mathrm{Co}$ irradiation $(2,4$ Gy). TRA- 8 was added $24 \mathrm{~h}$ after irradiation with the indicated concentrations. Cell viability was determined $24 \mathrm{~h}$ later by MTT assay. Cell viability was expressed as a percentage of untreated control cells, and there were 3 replicates in each assay. The results are derived from three experiments.

Determination of the clonogenic survival. Hep-2R cells were treated with $1000 \mathrm{ng} / \mathrm{ml}$ TRA-8 for $24 \mathrm{~h}$. Cells plated at increasing densities up to 30,000 cells in culture flasks were irradiated with single dose of $0,1,2,3,4,6,8,10$ Gy with the ${ }^{60} \mathrm{Co} \gamma$-rays (103.03 cGy/min). As a control, Hep-2R cells untreated with TRA-8 were irradiated. After being cultured for 12 days, the cells were stained with $1 \%$ crystal violet in absolute ethanol for $20 \mathrm{~min}$, and then we counted the colonies with $>50$ cells. Colonies were counted by three independent observers using an inverted microscope. Data were fitted according to a second order polynomal model.

Expression of DR5 in Hep-2R cells after irradiation. Cells in exponential growth phase were seeded in 24-well plates at a concentration of $5 \times 10^{5}$ cells/well overnight. Irradiation for 


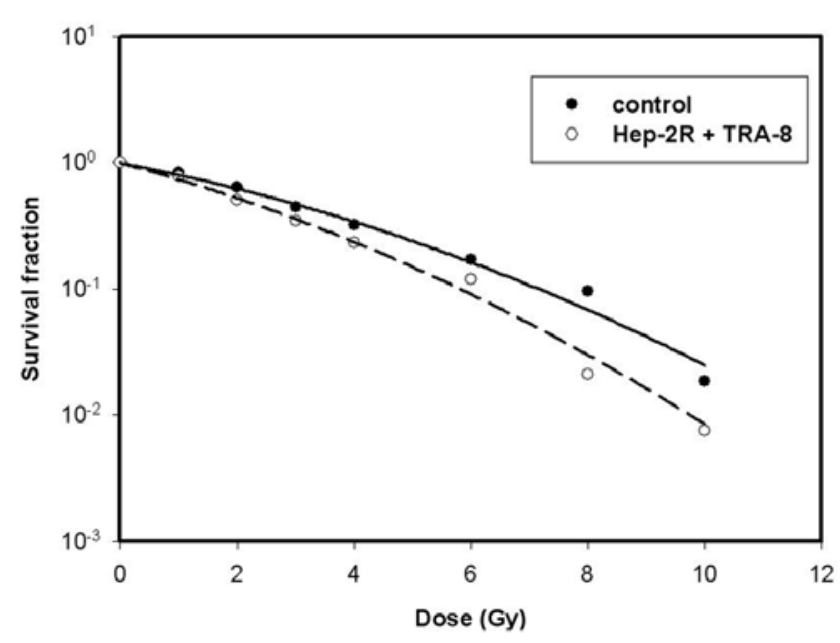

Figure 3. Survival curves of Hep-2R cells after $\gamma$ irradiation. Hep-2R cells were inoculated into $100 \mathrm{ml}$ culture flasks and treated with indicated doses of ${ }^{60} \mathrm{Co} \gamma$-ray in presence or absence of $1000 \mathrm{ng} / \mathrm{ml}$ TRA- 8 for $24 \mathrm{~h}$ before irradiation. Twelve days after irradiation, the cells were stained with $1 \%$ crystal violet in absolute ethanol for $20 \mathrm{~min}$, and the colonies with $>50$ cells were counted. Data are expressed as mean values of three independent observations. Data were fitted according to a second order polynomal model.

2 Gy with ${ }^{60} \mathrm{Co} \gamma$-ray, took cells untreated with irradiation as a control. After $24 \mathrm{~h}$, cells were harvested by centrifugation at $4^{\circ} \mathrm{C}$ for $5 \mathrm{~min}$ at $1,000 \mathrm{rpm}$, followed by resuspension in PBS at $4^{\circ} \mathrm{C}$. Cells were counted and aliquots of $5 \times 10^{5}$ cells were added to FACS tubes. Cells were recentrifuged and the pellet was resuspended in PBS. Cells were incubated with TRA-8 $(2 \mu \mathrm{g} / \mathrm{ml})$ for $40 \mathrm{~min}$ on ice followed by FITC-conjugated goat anti-mouse IgG antibody (Wuhan Boster Biological Technology, Ltd.). Cells were washed again with FACS buffer and were examined using flow cytometry (FACScan Beckman Coulter). Data were analyzed using CellQuest software.

Distribution of cell cycle. Different cell cycle phases (G1, S or G2/M phase) are characterized by different DNA contents. Fluorescence dye propidium iodide (PI) binds to DNA strongly at a ratio of $1: 1$, and hence the DNA contents of cell cycle phases are reflected by varying PI fluorescent intensities. Hep-2R cells were harvested by trypsinization $24 \mathrm{~h}$ after $1000 \mathrm{ng} / \mathrm{ml}$ TRA-8 treatment, and fixed in $70 \%$ ice-cold $\left(4^{\circ} \mathrm{C}\right)$ ethanol for $2 \mathrm{~h}$. Cell pellets were resuspended in $1 \mathrm{mg} / \mathrm{ml}$ RNase solution (Sigma) for $30 \mathrm{~min}$ at $37^{\circ} \mathrm{C}$, and then in $0.1 \mathrm{mg} /$ $\mathrm{ml}$ PI solution (Sigma) at $4^{\circ} \mathrm{C}$ for $1 \mathrm{~h}$ in the dark. Cell cycle analysis was performed on a flow cytometer (Beckman Coulter).

Statistical analyses. Statistical analyses were performed using the one-way ANOVA, Chi-square test or MannWhitney t-test, contained in the SPSS software package (version 13.0) for Windows and the difference was regarded as significant at $\mathrm{p}<0.05$.

\section{Results}

TRA-8 induced cytotoxicity in Hep-2R cells. We assessed TRA-8 induced apoptosis on Hep-2R cells alone (Fig. 1).
Table I. The parameters of surviving Hep-2R cells after different dose of irradiation. ${ }^{\text {a }}$

\begin{tabular}{lccc}
\hline Group & $\alpha\left(\mathrm{Gy}^{-1}\right)$ & $\beta\left(\mathrm{Gy}^{-2}\right)$ & $\mathrm{SF}_{2}$ \\
\hline Control & 0.2204 & 0.0138 & $0.61 \pm 0.0$ \\
TRA-8 & 0.2804 & 0.0193 & $0.53 \pm 0.0$ \\
\hline
\end{tabular}

${ }^{a}$ The parameters $\left(\alpha, \beta, \mathrm{SF}_{2}\right)$ of surviving of Hep-2R cells were from the survival curves (Fig. 3) according to a second order polynomal model. The $\mathrm{SF}_{2}$ in different groups had a significant difference $(\mathrm{P}<0.05)$.
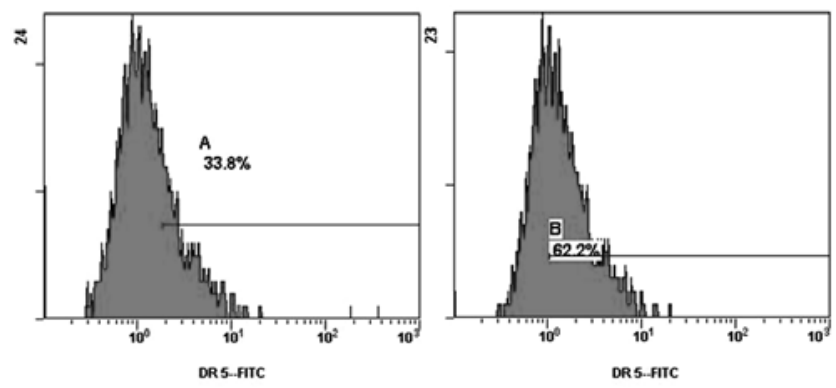

Figure 4. Effect of DR5 expression in Hep-2R cells after irradiation. (A) Expression of DR5 on Hep-2R cells. (B) Hep-2R cells were treated with 2 Gy ${ }^{60} \mathrm{Co} \gamma$-ray irradiation. Twenty-four hours later, cells were harvested, and incubated first with $2 \mu \mathrm{g} / \mathrm{ml}$ of TRA-8, then with goat anti-mouse IgG conjugated with fluorochrome. Cells were analyzed using FACScan and analyzed with CellQuest software. The expression of DR5 protein in Hep-2R cells after irradiation was conspicuously different from the cells without ionizing radiation.

The cell viability assay suggested that Hep-2R cells were resistant to TRA-8, for $\mathrm{IC}_{50}>1000 \mathrm{ng} / \mathrm{ml}$, and there was a synergistic cytotoxicity in Hep-2R cells treated with ionizing radiation followed by TRA-8 administration (Fig. 2).

TRA-8 reduces clonogenic survival after ionizing radiation. To investigate the combined effects of TRA-8 and ionizing radiation on Hep-2R cell survival, we also used long-term clonogenic assays that incorporate effects on cell cycle activity, apoptotic and non-apoptotic death. The survival curves were constructed (Fig. 3), and the parameters of radiosensitivity in cells were assayed (Table I). The survival fraction at 2 Gy $\left(\mathrm{SF}_{2}\right)$ for Hep-2R cells was significantly decreased by TRA-8. The result indicated that the Hep-2R cells treated with TRA- 8 before irradiation had a great enhancement in radiosensitivity. The steeper slope of the curve representing the combined treatment indicates that TRA-8 reduced clonogenic survival.

Regulation of death receptors by ionizing radiation. We analyzed the expression of DR5 in Hep-2R cells $24 \mathrm{~h}$ after $2 \mathrm{~Gy}{ }^{60} \mathrm{Co} \gamma$-ray irradiation. The data suggested that the expression of DR5 protein was induced by irradiation in Hep2R cell line (Fig. 4). After ionizing radiation, the expression of DR5 in Hep-2R cells increased to $(59.6 \pm 5.2) \%$ from $(36.9 \pm 3.5) \%(\mathrm{p}<0.05)$. 


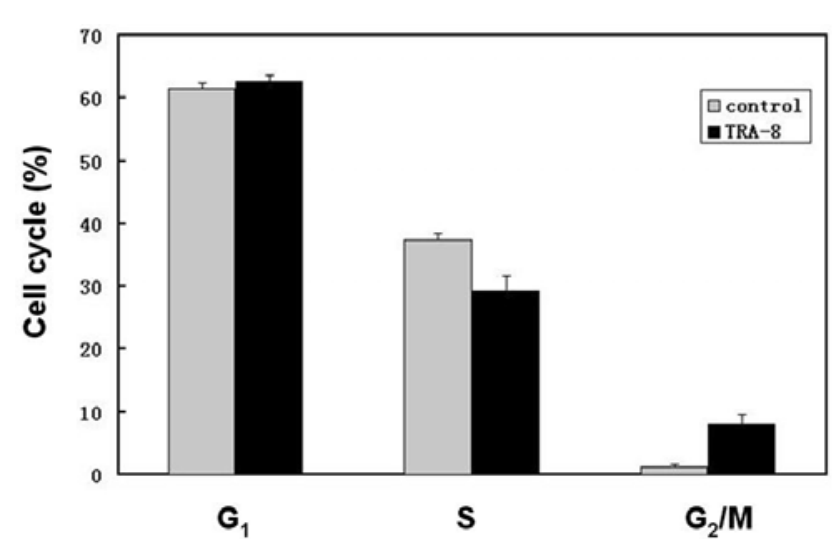

Figure 5. Change of cell cycle in Hep-2R after treatment with TRA-8. (Control) Hep-2R cells were not exposed to TRA-8; (TRA-8) Hep-2R cells were exposed to TRA-8 $(1000 \mathrm{ng} / \mathrm{ml})$ for $24 \mathrm{~h}$. At the end of incubation period, cell cycle was measured by PI staining flow cytometry. Data are expressed as means \pm SD of three independent observations. G1 phase $\mathrm{P}>0.05 ; \mathrm{S}$-phase $\mathrm{P}<0.01 ; \mathrm{G} 2 / \mathrm{M}$ phase $\mathrm{P}<0.01$.

Effects of TRA-8 on cell cycle. We analysed whether there were any changes in the redistribution of cell cycle following treatment with TRA-8. The data suggested that there was no change in the percentage of G1 phase after treatment with TRA-8 for $24 \mathrm{~h}$, nevertheless, the cell cycle revealed an increase in the percentage of G2/M phase and a decrease of $S$ phase (Fig. 5).

\section{Discussion}

TRAIL-R monoclonal antibody-mediated treatment has been shown to be effective in some cancer cell lines (20-22). Phase I/II trials in patients with advanced tumors evaluated the efficacy, safety and tolerability as single agent (23-27), and a phase II clinical trial on DR5 mAb is ongoing. Additional evaluation of this novel apoptosis-inducing agent, particularly in combination with radiotherapy and chemotherapy agents, is warranted.

In this study, we examined the effects of TRA-8, a mouse monoclonal antibody binding to human DR5, combination with ionizing radiation on Hep-2R cells. We found that the greatest survival benefit in Hep-2R cells was from the combination of TRA- 8 with radiation therapy. After ionizing radiation, the expression of DR5 in Hep-2R cells increased from $(36.9 \pm 3.5) \%$ to $(59.6 \pm 5.2) \%$. As our radioresistant cell line was made by repeated irradiation to human laryngocarcinoma Hep-2 cells, we examined the expression of DR5 on Hep- 2 cells, which was $27.6 \pm 1.0 \%$ (data not shown). This result indicated that ionizing radiation induced expression of DR5 not only in the short-term, but also in the long-term. Ionizing radiation significantly up-regulated the expression of DR5 in human carcinoma cells, even under hypoxia (2831). Unlike DR5, it has been reported that DR4 could not be induced by ionizing radiation (32). Thus, DR $5 \mathrm{mAb}$ might be a better choice for tumor therapy in combination with radiation therapy, as compared with DR4 mAb.

The clonogenic survival suggested that TRA-8 cut down the $\mathrm{SF}_{2}$ and significantly enhanced the radiosensitivity of
Hep-2R cells. TRA-8 regulates G2/M phase arrest, which could partially explain the mechanisms of enhancing radiosensitivity of Hep-2R cells by TRA-8. The changes in cell cycles indicated that cells in the radioresistant phase decreased and in radiosensitive phase increased. The regulation of the cell cycle observed in our study suggests that the complicated regulation mechanisms needed to be further investigated.

The TRA-8, murine monoclonal antibodies created from mice immunized with DR5, in combination with not only ionizing radiation, but with certain anti-tumor agents demonstrated synergistic anti-tumor activity, such as cisplatin, oxaliplatin, erlotinib, paclitaxel, CPT-11 (18,33-40). We will continue our study of TRA-8 on radioresistant cells in combination with other agents.

TRAIL may be a safer therapeutic agent than TNF and FasL (40-42), furthermore, TRAIL-R monoclonal antibodymediated treatment has more prospects for targeting treatment of cancers that express death receptors. The present investigation enhances our understanding of the radiation mechanism of radiation and TRA-8-induced apoptosis. The observed synergy between TRA- 8 and therapeutic doses of radiation can form the basis for developing strategies for pharmacological intervention, with potential for clinical application.

\section{Acknowledgements}

We would like to thank Professor Virginia Robey for English revision. This work was supported by a grant from Keji Gongguan Project of Hubei Province (No. 2005AA304B04).

\section{References}

1. Britten PA and Evans AJ: Intratumoral heterogeneity as a confounding factor in clonogenic assays for tumor radioreponsiveness. Radiother Oncol 139: 145-153, 1996.

2. Pelevina II, Gotlib VI, Kudriashova OV, Antoshchina MM and Serebrianyi AM: Properties of progeny of irradiated cells. Tsitologiia 40: 467-477, 1998

3. Luo ZG, Zhou FX, Zhou YF, Xie CH, Dai J and Liu SQ: Radiation-induced radioresistant human squamous carcinoma cell line and its biological characteristics. Zhonghua Fang She Zhong Liu Za Zhi 14: 208-212, 2005.

4. Ashkenazi A, Pai RC, Fong S, Leung S, Lawrence DA and Marsters SA: Safety and antitumor activity of recombinant soluble Apo2 ligand. J Clin Invest 104: 155-162, 1999.

5. Pan G, ORourke K and Chinnaiyan AM: The receptor for the cytotoxic ligand TRAIL. Science 276: 111-131, 1997.

6. Chaudhary PM, Eby M, Jasmin A, Bookwalter A, Murray J and Hood L: Death receptor 5, a new member of the TNFR family, and DR4 induced FADD-dependent apoptosis and activate the NF-кB pathway. Immunity 7: 821-830, 1997.

7. Walczak H, Degli-Esposti MA, Johnson RS, Smolak PJ, Waugh JY and Boiani N: TRAIL-R2: a novel apoptosismediating receptor for TRAIL. EMBO J 16: 5386-5397, 1997.

8. Marsters SA, Sheridan JP and Pitti RM: Identification of a ligand for the death-domain-containing receptor Apo3. Curr Biol 8: 525-530, 1998 .

9. Degli-Esposti MA, Smolak PJ and Walczak H: Cloning and characterization of TRAIL-R3 a novel member of the emerging TRAIL receptor family. J Exp Med 186: 1165-1170, 1997.

10. Sheridan JP, Marsters SA and Pitti RM: Control of TRAILinduced apoptosis by a family of signaling and decoy receptors. Science 277: 818-821, 1997

11. Emery JG, McDonnell P and Burke MB: Osteoprotegerin is a receptor for the cytotoxic ligand TRAIL. J Biol Chem 273: 14363-14367, 1998.

12. Jo M: Apoptosis induced in normal human hepatocytes by tumor necrosis factor-related apoptosis-inducing ligand. Nat Med 6: 564-567, 2000. 
13. Almasan A and Ashkenazi A: Apo2L/TRAIL: Apoptosis signaling, biology, and potential for cancer therapy. Cytokine Growth Factor Rev 14: 337-348, 2003.

14. Lawrence D: Differential hepatocyte toxicity of recombinant Apo2L/TRAIL versions. Nat Med 7: 383-385, 2001.

15. Ichikawa K, Liu W, Zhao L, Wang Z, Liu D and Ohtsuka T: Tumoricidal activity of a novel anti-human DR5 monoclonal antibody without hepatocyte cytotoxicity. Nat Med 7: 954-960, 2001.

16. Pukac L: HGS-ETR1, a fully human TRAIL-receptor 1 monoclonal antibody, induces cell death in multiple tumour types in vitro and in vivo. Br J Cancer 92: 1430-1441, 2005.

17. Buchsbaum DJ, Zhou T, Grizzle WE, Oliver PG, Hammond CJ and Zhang S: Antitumor efficacy of TRA-8 anti-DR5 monoclonal antibody alone or in combination with chemotherapy and/or radiation therapy in a human breast cancer model. Clin Cancer Res 9: 3731-3741, 2003.

18. Straughn JM Jr, Oliver PG, Zhou T, Wang W, Alvarez RD and GrizzleWE: Anti-tumor activity of TRA-8 anti-death receptor 5 (DR5) monoclonal antibody in combination with chemotherapy and radiation therapy in a cervical cancer model. Gynecol Oncol 101: 46-54, 2006.

19. Estes JM, Oliver PG, Straughn JM Jr, Zhou T, Wang W and Grizzle WE: Efficacy of anti-death receptor 5 (DR5) antibody (TRA-8) against primary human ovarian carcinoma using a novel ex vivo tissue slice model. Gynecol Oncol 105: 291-298, 2007.

20. Zeng Y, Wu XX, Fiscella M, Shimada O, Humphreys R, Albert V and Kakehi Y: Monoclonal antibody to tumor necrosis factorrelated apoptosis-inducing ligand receptor 2 (TRAIL-R2) induces apoptosis in primary renal cell carcinoma cells in vitro and inhibits tumor growth in vivo. Int J Oncol 28: 421-430, 2006.

21. Marini P, Denzinger S, Kauder S, Schiller D, Welz S, Jendrossek $\mathrm{V}$, Budach $\mathrm{W}$ and Belka $\mathrm{C}$ : In vitro and in vivo effects after combined treatment of colorectal tumors with apoptosis inducing trail receptor antibodies HGS-ETR 1 and HGS-ETR2 and radiotherapy. Radiot Oncol 78: S75, 2006.

22. Natoni A, MacFarlane M, Inoue S, Walewska R, Majid A, Knee D, Stover DR, Dyer MJ and Cohen GM: TRAIL signals to apoptosis in chronic lymphocytic leukaemia cells primarily through TRAIL-R1 whereas cross-linked agonistic TRAIL-R2 antibodies facilitate signalling via TRAIL-R2. Br J Haematol 139: 568-577, 2007

23. Attard G, Plummer RE and De Bono JS: Phase 1 and pharmakinetic study of HGS-ETR2, a fully human agonistic monoclonal antibody to TRAIL-R2, in patients with advanced solid malignancies. Clin Cancer Res 11: S9060, 2005

24. Plummer R, Attard G, Pacey S, Li L, Razak A, Perrett R, Barrett M, Judson I, Kaye S, Fox NL, Halpern W, Corey A, Calvert $\mathrm{H}$ and de Bono $\mathrm{J}$ : Phase 1 and pharmacokinetic study of lexatumumab in patients with advanced cancers. Clin Cancer Res 13: 6187-6194, 2007.

25. Hirte HW, Hotte SJ, Chen EX, et al: HGS-ETR1, a fully human agonistic monoclonal antibody to the tumor necrosis factorrelated apoptosis-inducing ligand receptor 1 (TRAIL-R1) in patients with advanced solid cancer: results of a phase 1 trial. Clin Cancer Res 11: S9104, 2005.

26. Mita MT, Tolcher AW and Patnaik A: A phase I, pharmacokinetic (PK) study of HGS-ETR1, an agonist monoclonal antibody to TRAIL-R1, in patients with solid tumors. Proc Am Assoc Cancer Res 46: 544, 2005.

27. Greco FA: Phase 2 study of mapatumumab, a fully human agonistic monoclonal antibody which targets and activates the TRAIL receptor-1, in patients with advanced non-small cell lung cancer. Lung Cancer 61: 82-90, 2008.

28. Hamasu T, Inanami O, Asanuma T and Kuwabarb M: Enhanced induction of apoptosis by combined treatment of human carcinoma cells with $\mathrm{X}$ rays and death receptor agonists. J Radiat Res 46: 103-110, 2005.
29. Takahashi M, Inanami O, Kubota N, Tsujitani M, Yasui $\mathrm{H}$, Ogura A and Kuwabara M: Enhancement of cell death by TNF alpha-related apoptosis-inducing ligand (TRAIL) in human lung carcinoma A549 cells exposed to x rays under hypoxia. J Radiat Res 48: 461-468, 2007.

30. Kimura K and Gelmann EP: Tumor necrosis factor-alpha and Fas activate complementary Fas-associated death domaindependent pathways that enhance apoptosis induced by gammairradiation. J Biol Chem 275: 8610-8617, 2000.

31. Shankar S, Singh TR and Srivastava RK: Ionizing radiation enhances the therapeutic potential of TRAIL in prostate cancer in vitro and in vivo: intracellular mechanisms. Prostate 61: 35-49, 2004.

32. Shankar S, Singh TR and Chen X: The sequential treatment with ionizing radiation followed by TRAIL/Apo-2L reduces tumor growth and induces apoptosis of breast tumor xenografts in nude mice. Int J Oncol 24: 1133-1140, 2004

33. Fiveash JB, Gillespie GY, Oliver PG, Zhou T, Belenky ML and Buchsbaum DJ: Enhancement of glioma radiotherapy and chemotherapy response with targeted antibody therapy against death receptor 5. Int J Radiat Oncol Biol Phys 71: 507-516, 2008.

34. Ohtsuka T, Buchsbaum D, Oliver P, Makhija S, Kimberly R and Zhou T: Synergistic induction of tumor cell apoptosis by death receptor antibody and chemotherapy agent through JNK/p38 and mitochondrial death pathway. Oncogene 22: 2034-2044, 2003.

35. Long JW, Derosier LC, Vickers SM, Sellers J, Wang W, Arnoletti JP and Buchsbaum DJ: TRA-8 (TRAIL-R2 antibody) based combination chemotherapy produces a survival benefit in a pancreatic cancer orthotopic model. J Surg Res 137: 167 , 2007.

36. Oliver PG, LoBuglio AF, Zinn KR, Kim H, Nan L, Zhou T, Wang W and Buchsbaum DJ: Treatment of human colon cancer xenografts with TRA-8 anti-death receptor 5 antibody alone or in combination with CPT-11. Clin Cancer Res 14: 2180-2189, 2008.

37. Kendrick JE, Straughn JM Jr, Oliver PG, Wang W, Nan L, Grizzle WE, Stockard CR, Alvarez RD and Buchsbaum DJ: Anti-tumor activity of the TRA-8 anti-DR5 antibody in combination with cisplatin in an ex vivo human cervical cancer model. Gynecol Oncol 108: 591-597, 2008.

38. Long JW, Buchsbaum DJ, Sellers J, Huang Z, Vickers SM and Arnoletti P: Erlotinib reduces flip mediated resistance to TRA-8 agonistic TRAIL-R2 antibody in pancreatic cancer cells. J Surg Res 144: 387-388, 2008

39. Gong J, Yang D, Kohanim S, Humphreys R, Broemeling L and Kurzrock R: Novel in vivo imaging shows up-regulation of death receptors by paclitaxel and correlates with enhanced antitumor effects of receptor agonist antibodies. Mol Cancer Ther 5: 2991-3000, 2006.

40. Tartaglia LA and Goeddel DV: Tumor necrosis factor receptor signaling. A dominant negative mutation suppresses the activation of the $55-\mathrm{kDa}$ tumor necrosis factor receptor. J Biol Chem 267: 4304-4307, 1992.

41. Havell EA, Fiers W and North RJ: The antitumor function of tumor necrosis factor (TNF) I Therapeutic action of TNF against an established murine sarcoma is indirect, immunologically dependent, and limited by severe toxicity. J Exp Med 167: 1067-1085, 1988

42. Ogasawara J, Watanabe-Fukunaga R, Adachi M, Matsuzawa A, Kasugai T, Kitamura Y, Itoh N, Suda T and Nagata S: Lethal effect of the anti-Fas antibody in mice. Nature 364: 806-809, 1993. 